\title{
Testimonios
}

\section{Un infortunio incierto y una incierta afortunada}

\section{L. Álvarez Martínez}

Aquella semana parecía ser como las demás, sin nada especial. Se rumoreaba que había un virus al que llamaban «covid-19», que muchas personas calificaban como una simple gripe y otras veían como algo más alarmante, casi apocalíptico. Varias universidades españolas ya habían cerrado sus puertas. En consecuencia, el estudiantado, el profesorado y el personal de administración y servicios estaban en sus respectivas casas. Yo, una estudiante del primer curso del Grado en Ciencias del Lenguaje y Estudios Literarios de la Universidad de Vigo, todavía podía continuar las clases presencialmente, pues esta universidad aún no había sido cerrada. Con todo, el personal docente, al menos en su mayoría, ya intuía que de un día para otro nos veríamos impartiendo docencia desde nuestras casas, sin saber cómo tendríamos que enfocar la situación para que el curso se pudiese desarrollar con éxito. Cada día que llegábamos a clase era un día más que avanzábamos en las correspondientes materias, sin saber cómo se desarrollarían nuestras vidas al día siguiente. En resumen, todo, desde el comienzo, era caótico e incierto.

En la academia de inglés en la que me preparaba para examinarme del nivel B2 de Cambridge pasaba lo mismo. No sabían cuándo, si es que llegaba el día, tendrían que cerrar sus puertas y continuar virtualmente su trabajo. Tampoco tenían idea de cómo seguirían las clases si eso llegaba a ocurrir.

En esta situación, el plano personal parecía el más esperanzador, dadas las circunstancias: continuaba el contacto presencial con las personas de mi entorno y aún podía ir a nadar cada viernes a una piscina de mi ciudad. Mi vida no se había visto alterada. No se había visto alterada hasta aquel día, aquella tarde de jueves en la que esta pesadilla comenzó a cobrar tonos totalmente oscuros. Bien es sabido que el estado de alarma y el cese de todas las actividades presenciales, excepto las indispensables, 
llegaron el sábado 14 de marzo. Entonces, ¿por qué tuvo tal importancia el jueves de esa misma semana? Porque un aviso, un mensaje, cambiaría mi vida por completo.

La tarde del jueves 12 de marzo de 2020 se anunció que, en Galicia, sería voluntario que el estudiantado acudiese a los centros educativos al día siguiente. Además, la semana siguiente ya estarían todos los centros educativos de esta comunidad autónoma cerrados. Yo no sabía si la profesora con la que teníamos clase al día siguiente iba a impartir docencia o si, por el contrario, aquel había sido el último día de clases presenciales hasta que pudiésemos retomarlas. Finalmente, el aviso de que al día siguiente no tendríamos clase de la materia que correspondía disipó mis dudas. A lo largo de la tarde fueron llegando muchas otras suspensiones: la ONCE informó de que las actividades de animación sociocultural quedaban aplazadas, me llamaron del gimnasio al que iba a nadar para decirme que sería optativo ir al día siguiente... A esto hay que sumar que nadie sabía lo que acontecería en los próximos días ni cómo podrían seguir ofreciendo los mismos servicios de otro modo, del único modo posible: virtualmente.

Todo eso me preocupaba, o, más rigurosamente, nos preocupaba. Con todo, en cada caso, la situación y las implicaciones de estas nuevas medidas eran diferentes. Para mí, todo lo que acontecía era incierto y agobiante, más de lo que ya lo era per se si tenemos en cuenta que, si la vida hubiese seguido su curso sin mayores alteraciones, yo tendría exámenes la siguiente semana. Con esta nueva situación, nadie sabía cómo podríamos examinarnos. Ese fin de semana, al igual que las semanas siguientes, resultó ser caótico: los correos electrónicos me llegaban masivamente, y en todos se hablaba de posibles soluciones, nuevas medidas, información relativa a la situación pandémica y buenos deseos para nosotros y nuestras personas queridas.

Finalmente, el sábado 14 de marzo se decretó el estado de alarma. Tiendas, comercios, cafeterías, centros culturales y recreativos, templos religiosos y un sinfín de establecimientos tuvieron que cerrar sus puertas. La venta de los productos de juego de la ONCE no fue una excepción. Solamente permanecieron abiertos los establecimientos esenciales e indispensables, como las tiendas de alimentos y las farmacias, entre otros. La mayor parte de las actividades se suspendieron, lo que supuso el comienzo de la decadencia económica de un gran número de personas y familias, así como el inicio de una crisis mundial en la que aún nos encontramos. Estas medidas preventivas se extendieron por todo el país y, en mayor o menor grado, por todo el mundo. Repentinamente, nos hallamos en un encierro, al que llamaron «confinamien- 
to». Las llaves de nuestra libertad estaban en posesión del Gobierno y de la Xunta de Galicia, que actuarían en función de la incidencia del coronavirus (o covid-19) y de la responsabilidad de la ciudadanía.

En este sentido, entre el jueves 12 y el sábado 14 de marzo de 2020, mis relaciones sociales se redujeron progresivamente, hasta que solamente me relacionaba en persona con mis padres, con quienes convivo. Así, el contacto con otras personas dependía de las posibilidades que ofrecía la tecnología, especialmente las llamadas y los mensajes. En este escenario transcurrieron dos meses, aproximadamente, en los que no nos permitían ver a familiares cercanos y a personas muy queridas. Todavía hoy, por precaución, no podemos reunirnos con personas con las que tenemos una relación muy próxima.

La situación ha sido -y es- complicada. Sin embargo, el confinamiento iniciado el 14 de marzo se diferenciaba de la situación actual en un aspecto que, a mi juicio, es relevante: solamente se podía salir del domicilio para realizar actividades indispensables e inaplazables, tales como acudir a una cita médica, trabajar o comprar productos de primera necesidad, entre otras. Esta situación de desesperación por el encierro y la comunicación con el exterior reducida a pantallas, la prensa y las actividades esenciales anteriormente citadas, se vio agravada por las circunstancias particulares de cada persona o familia. La soledad, el aburrimiento y las dificultades para acceder a determinados servicios o productos son tres ejemplos de los muchos que se podrían mencionar en lo que atañe a los factores que incrementaron la desesperación y la frustración, prácticamente, durante dos interminables meses.

En este contexto, yo era afortunada. Puede resultar rara o extraña esta afirmación, pero lo cierto es que así me sentía. Por una parte, aunque al principio no estaba claro el modo como íbamos a continuar las clases en la academia y en la universidad, rápidamente comenzamos a recibir tareas e instrucciones para aprender y poder superar el curso, que terminaría irremediablemente en línea. Para lograr esta eficiencia fueron trascendentales el apoyo, la comprensión y la empatía del profesorado, tanto de la universidad como de la academia de inglés. Por mi parte, traté de estar a la altura de las circunstancias: si bien no teníamos clases telemáticas de todas las materias, intenté no perder el ritmo y respetar los horarios de docencia que tenía fijados antes de la irrupción de la pandemia en nuestras vidas. De esta forma, los trabajos, los ejercicios, los exámenes, los apuntes y las clases en línea evitaron que pudiese aburrirme. El poco tiempo que me quedaba libre lo dedicaba a actividades de ocio que se pueden realizar desde casa. 
Por otra parte, el hecho de que mi casa tenga terreno constituye la otra causa que explica mi situación ventajosa en comparación con la de muchas otras personas que viven en pisos sin balcón o en casas sin terreno ni terraza. Esta posibilidad de disfrutar de la naturaleza en mi domicilio, unida al buen tiempo -incluso soleado- que caracterizó numerosos días de confinamiento, propiciaron que, por las tardes, en lugar de estudiar en el interior de la casa, me decantase por realizar mis tareas al aire libre, sin salir de los límites del domicilio.

En definitiva, las múltiples tareas académicas y la disponibilidad de acceder a la naturaleza en cualquier momento me convirtieron en una incierta afortunada, esto es, en una afortunada, a pesar del infortunio incierto que nos había tocado vivir. Este infortunio, la pandemia, era $-\mathrm{y}$ es - incierto para todas las personas debido a los cambios frecuentes en las medidas preventivas adoptadas y a las diferencias entre las distintas comunidades autónomas o regiones en lo que a ellas se refiere. $Y$ fue en uno de estos giros de nuestra situación, acontecido a comienzos de mayo, cuando, finalmente, pudimos salir a caminar por los alrededores de nuestras respectivas residencias. Los aplausos al personal sanitario que habían estado presentes durante el confinamiento todos los días a las ocho de la noche y que habían servido de punto de encuentro del vecindario, ahora ya no formaban parte de la rutina. La razón por la cual se dejó este hábito es que, precisamente, era a las ocho cuando las personas adultas podíamos salir a caminar. Aquellos paseos eran agradables, pero también, en mi opinión, sorprendentes, pues nada era igual desde marzo: había más pájaros, el ambiente estaba menos contaminado a consecuencia de la reducción de la actividad humana y la gente valoraba más salir a correr o a pasear cuando llegaba la hora en que podía hacerlo. El número de coches que circulaban cerca de mi casa se redujo considerablemente. En líneas generales, la gente apreciaba más los pequeños detalles, aquello a lo que no se le había dado tanta importancia porque siempre lo habíamos tenido. Poder salir a la calle se convirtió en nuestro bien más preciado; las mascarillas, en nuestras compañeras de batalla.

Así contado, puede parecer que el desconfinamiento fue el acontecimiento más grato del año. Nada más lejos de la realidad. Si bien, al menos para mí, fue positivo comenzar a salir a la calle, el agobio del confinamiento fue sustituido por la claustrofobia derivada de utilizar la mascarilla durante largo tiempo. Así transcurrió todo el verano. Por suerte, en mi casa montamos una piscina, de manera que evitamos las aglomeraciones de las playas. Nuevamente volví a sentirme afortunada. 
Cuando terminó el verano y comenzó el nuevo curso académico, continué las clases presenciales en la academia, las cuales ya habían comenzado en junio. En lo que se refiere a la universidad, al ser la carrera que estoy cursando una titulación en la que el número de estudiantes es reducido, todas las clases eran presenciales. En otros grados se combinaba la presencialidad con la virtualidad o todo se desarrollaba telemáticamente. Así transcurrió el primer cuatrimestre, es decir, el período comprendido entre septiembre y enero. Mi cara se adaptó a estar cubierta por una mascarilla un mínimo de cuatro horas diarias y un máximo de ocho, cuando tenía clases en la universidad y en la academia en un mismo día. Pero esta no fue la única adaptación necesaria. Era preciso seguir las indicaciones y las medidas de seguridad ya propuestas desde el comienzo del desconfinamiento: distancia interpersonal, desinfección de los lugares e instrumentos de uso público que se hayan utilizado. El gel hidroalcohólico y las clases con mesas libres eran la «nueva normalidad» para que se pudiesen desarrollar lecciones magistrales, prácticas, exámenes $y$, en fin, toda clase de actividades formativas. En lo que respecta a la natación, todavía no la he retomado, pues he decidido ser prudente y esperar a que la situación sanitaria mejore, al menos en parte, para volver a practicar este deporte.

No obstante, en el segundo cuatrimestre, concretamente en febrero, la situación volvió a cambiar radicalmente. De un día para otro, nos comunicaron que el inicio de las clases universitarias se retrasaría una semana, como ya había ocurrido en septiembre, pero que, esta vez, no serían presenciales, sino virtuales, independientemente de la titulación y de la universidad, siempre que los estudios se cursasen en una universidad gallega. Para esa fecha yo ya había terminado las clases en la academia y me había examinado, por lo que me vi en mi casa, sin tener que ir a ninguna parte, prácticamente «confinada». Por mi experiencia, la docencia telemática no es igual que la presencial: pueden surgir problemas técnicos que retrasen alguna actividad y la interacción no es tan espontánea y natural, aunque es cierto que, al menos en las plataformas de docencia empleadas por la Universidad de Vigo, existe la posibilidad tanto de escribir en el chat como de hablar utilizando el micrófono. Con todo, si tuviese que indicar la modalidad predilecta, para mí sería la presencial. Es evidente que actualmente es necesario realizar actividades en línea para garantizar la salud de quienes participan en ellas y reducir los contagios, pero, en las condiciones habituales antes de la irrupción de la pandemia, la presencialidad permitía una mayor interacción con las demás personas que participaban en una actividad o proceso formativo determinado, potenciando, así, las relaciones sociales o interpersonales. Afortunadamente, el lunes 1 de marzo se reanudaron las clases universitarias pre-

Álvarez, L. (2021). Un infortunio incierto y una incierta afortunada. RED Visual: Revista Especializada en Discapacidad Visual, 77, 348-354. https://doi.org/10.53094/MTMC3221. 
senciales en toda Galicia en aquellas titulaciones en las que se desarrollaron así en el primer cuatrimestre.

Puede parecer que en el ámbito universitario todo es confuso y las medidas adoptadas no son congruentes, estables y claras. No obstante, como ya se ha apuntado, el educativo no es el único sector caracterizado por las incertezas y las decisiones cambiantes. Todos los ámbitos de la vida humana se han visto y se ven alterados por las decisiones políticas desde el inicio de la pandemia. Actividades que quizás nunca nos planteamos que no podríamos realizar, tales como tomar un café, ir a un museo o al cine, ver una obra de teatro o estudiar en la biblioteca, se han convertido en alternativas que hoy pueden ser viables y mañana no, o viceversa. La evolución de la pandemia, la sobreinformación relativa al coronavirus y las medidas de prevención de los contagios, que cambian periódicamente y tienen repercusiones políticas y socioeconómicas, han sido y son las causas de graves problemas de la sociedad. Estos problemas no son solo físicos, los cuales son obvios, al ser causados por el contagio de la covid-19, sino también psicológicos. Expertos y expertas subrayan la importancia de la ansiedad, la depresión y numerosos trastornos psicológicos que padecen o padecerán muchas personas a causa de la situación actual. Además, en lo relativo a las patologías físicas, ya se ha mencionado la covid-19, pero existen otras que se ven agravadas porque, en muchos casos, debido a que se invierte más esfuerzo físico y material en el coronavirus, no son diagnosticadas a tiempo o se diagnostican tardíamente, provocando incluso el fallecimiento de un gran número de personas. Por este motivo, es preciso destacar la relevancia de tener una mente abierta en el ámbito sanitario: no todas las patologías se llaman «coronavirus» ni todas las personas enfermas son víctimas de la pandemia. Por ello, en los hospitales, es necesario emplear un esfuerzo material y físico equitativo para todas las personas, de manera que se intente diagnosticar y tratar cualquier patología partiendo de la base de que no tiene por qué ser coronavirus.

En síntesis, la situación actual es compleja y más desfavorable para unas personas que para otras. Desde mi punto de vista, las consecuencias de la pandemia, tanto físicas como psicológicas, continuarán en la posguerra, tras una guerra en la que todas las personas somos enemigas y el arma de combate se llama «coronavirus». En este sentido, yo soy afortunada: en el plano personal, mi casa tiene terreno, por lo que puedo disfrutar de la naturaleza; en el profesional, continúo con mi rutina académica. Es cierto que las actividades formativas y de ocio, en su mayor parte, se desarrollan en línea, y ello puede ocasionar que sean menos llevaderas. También es verdad que la 
confusión que nos rodea en lo que se refiere a las medidas de seguridad, que cambian continua y repentinamente, no ayuda a establecer una rutina acorde a las circunstancias. Sin embargo, con la responsabilidad y la empatía colectivas, lograremos que este infortunio termine. Es probable que no consigamos que este virus desaparezca por completo, pero es cierto que llegará una «nueva normalidad». Nuestras vidas han cambiado, pero nada parece indicar que se encuentran en un punto de no retorno.

\section{Lucía Álvarez Martínez}

